\title{
ENTRE MEMÓRIAS SILENCIADAS DE UNGULANI BA KA KHOSA E VIRGEM MARGARIDA DE LiCINiO DE AZEVEDO: ESPAÇOS E MEMÓRIAS
}

\author{
Teresa Manjate
}

\begin{abstract}
RESUMO
O presente artigo tem como objecto de estudo duas narrativas: Entre memórias silenciadas de Ungulani ba ka Khosa (romance) e Virgem Margarida de Licinio de Azevedo (filme de ficção). A aproximação das duas obras é sugerida pela exploração temática - o processo de "reeducação" de uma franja da sociedade que é tida pelas instituições de poder como marginal ou desviada dos ideais da nova nação, em campos afastados das cidades. Pretende-se, numa perspectiva comparada, reflectir sobre as duas narrativas, a partir da análise dos espaços - topoanálise - relacionando esta categoria da narrativa com a memória: entre a individual e a colectiva.
\end{abstract}

\section{ENTRE MEMÓRIAS SILENCIADAS BY UNGULANI BA KA KHOSA AND VIRGEM MARGARIDA BY LICINIO DE AZEVEDO: SPACES AND MEMORIES}

\begin{abstract}
The present article has as object to study two narratives: Between Silent Memories by Ungulani ba ka Khosa (novel) and Virgin Margarida de Licinio de Azevedo (fiction film). The approximation of the two works is suggested by the thematic exploration - the process of "re-education" of a fringe of society that is held by institutions of power as marginal or diverted from the ideals of the new nation in fields far from the cities. It is intended, in a comparative perspective, to reflect on the two narratives, from the analysis of spaces - topoanalysis - relating this category of narrative to memory: between individual and collective ones.
\end{abstract}

KEYWORDS

Re-education camps; spaces; memories; imaginary

\section{INTRODUÇÃO}

O presente artigo tem como objecto de estudo duas narrativas: Entre memórias silenciadas de Ungulani ba ka Khosa (romance) e Virgem Margarida de Licinio de Azevedo (filme de ficção). A aproximação das duas obras é sugerida pela exploração temática - o processo de "reeducação" de uma franja da sociedade que é tida pelas instituições de 
poder como marginal ou desviada dos ideais da nova nação, em campos afastados das cidades. Pretende-se, numa perspetiva comparada, refletir sobre as duas narrativas, a partir da análise dos espaços - topoanálise - relacionando esta categoria da narrativa com a memória: entre a individual e a colectiva, processos de reconhecimento e de inscrição de experiências de vida em Moçambique - esquecidas ou silenciadas - visando trazer à luz uma proposta de debate sobre aspectos sociais e culturais muito representados nas obras.

As obras em estudo são autónomas, porém em ambos os casos nota-se uma ligação profunda com dois textos antecedentes. Virgem Margarida (2012) nasce na sequência do documentário A última prostituta (1999), do mesmo autor, Licinio de Azevedo; Entre memórias silenciadas (2013) parece estar intimamente ligada a No reino dos abutres (2002), do mesmo autor, Ungulani ba ka Khosa.

A aproximação das duas obras fundamenta-se na temática por elas explorada, o processo de reeducação de cidadãs e cidadãos tidos, pelas instituições de poder do pós-independência, como reflexo de uma sociedade decadente, a capitalista colonial, e com comportamentos incompatíveis com os ideais da nação moçambicana.

Em 1974, a revista Tempo, um dos periódicos mais emblemáticos e sistemáticos das décadas de 70,80 e 90 do século passado, documenta uma discussão dinâmica em torno da figura da prostituta, convocando visões diferentes: entre benevolentes e protetoras, tomando-as como mulheres vulneráveis e exploradas, vítimas do regime capitalista-colonial, ora incriminatórias, tomando-as como figuras alienadas a serem rejeitadas, transformadas ou recuperadas, para uma integração plena na sociedade. $A$ título de exemplo, Albino Magaia assina um texto com o título "Prostituição - tráfico de sexo mata fome", adiantando que "mais de 75.000 mulheres vendem o corpo em Lourenço Marques" (1974, p. 21). Neste artigo, as prostitutas são vistas como vítimas de um sistema que não dava alternativas de sobrevivência para aquelas mulheres. Outros artigos, no entanto, apresentam uma visão condenatória, defendendo a ideia de que elas não tinham lugar na sociedade. A sua integração dependeria do nível de transformação, através de um trabalho ideológico profundo.

A mensagem do presidente da FRELIMO, Samora Machel, ainda do Governo de Transição, anuncia mudanças de fundo como "Combate à alienação" em que apela para o dever de se lançar um

combate sem tréguas contra as sequelas do colonialismo, (...) valores decadentes, as ideias erradas (...); Sobre a "libertação da mulher (...) uma das frentes principais de batalha para a autêntica libertação da mulher do nosso povo é a da emancipação da mulher. Dois pesos esmagam hoje a mulher moçambicana: dum lado as tradições reacionárias que a privam de iniciativas no seio da sociedade e a reduzem a simples instrumento do homem (...) Temos, em particular, de pôr termo imediatamente a essa expressão sumariamente degradante do sistema colonial-capitalista que é a prostituição, a venda do corpo como se de uma loja se tratasse. (Machel, 1974, p. 12) 
Um artigo assinado por Calane da Silva documenta que, ainda no Governo de Transição, começam a surgir, nas cidades, as primeiras rusgas de prostitutas, um exercício que visava tirá-las das ruas e "reeducá-las". "A rusga efetuada no início do ano é a primeira tentativa de integração das mulheres alienadas da Rua Araújo na sociedade" (Calane da Silva, 1975, p. 36).

A história de Margarida, nome que dá título à obra cinematográfica Virgem Margarida, é inspirada nas memórias de um grupo de mulheres que, com uma história de vida ligada aos campos de reeducação - reeducandas e reeducadoras, as comandantes, fazem depoimentos em A última prostituta. Neste filme documentário, aquelas mulheres partilham as suas memórias e mencionam amiúde a história de uma menina, virgem, a Margarida, que foi levada com elas para o campo de reeducação, por ter estado no lugar errado na hora errada. Noiva de um jovem mineiro a trabalhar nas minas da África do Sul, ela tinha viajado da província de Gaza para a cidade de Maputo, na companhia de uma tia, a fim de fazer compras para o seu casamento. No contexto das rusgas, por não ter documentos e não ter convencido os soldados da sua "inocência", foi levada para os campos de reeducação. Muito jovem e com vivência rural, não entendia a vivência urbana, particularmente a linguagem e as atitudes das outras mulheres, da cidade, com quem tivera de partilhar a viagem e o processo de reeducação.

Esta jovem merece o lugar de destaque em Virgem Margarida. Ao longo da história, Margarida ganha a pouco e pouco a confiança e a simpatia das companheiras e, no final, ela é uma das motivações mais fortes para a rebelião, momento catártico do filme.

No documentário A última prostituta, as imagens e os discursos constituem-se como pano de fundo de todo o cenário: a euforia das rupturas - o fim de uma época do período colonial - e o prenúncio de uma nova vida, conquistada em 1974, quando se anuncia o fim da Luta de Libertação Nacional e se instala o Governo de Transição. Este filme inicia com Ricardo Rangel a mostrar e a comentar uma série de fotografias. As fotografias e as imagens captadas são significativas. Uma delas mostra uma prostituta ladeada de dois jovens militares a que o fotógrafo intitulou A última prostituta, nome que dá título ao documentário.

No filme Virgem Margarida, o mote está presente ao longo da película. Estão muito presentes as retóricas oficial e popular: uma vida nova, a formação do "Homem Novo", que parte de uma sociedade nova sem prostituição, sem bandidos, marginais, "desvios", muito de acordo com o discurso e a visão trazidos pela independência. O filme inicia com um camião em movimento, cheio de mulheres, e ornamentado com panfletos com palavras de ordem, com particular destaque para. A luta continua, escrito em letras garrafais. As mulheres cantam um hino revolucionário em Xichangana:

A hiyene a masinwuiniya povo

A hiyene a masinwuiniya povo

hi ta gwala a tintsmba ta hina...

[Vamos à machamba do povo/vamos à machamba do povo/

para semear as nossas riquezas] 
Depois, apresenta-nos rusgas' em bares e casas de prostituição e nas ruas, onde mulheres são recolhidas coercivamente e metidas em camiões. Em caravanas de machimbombos, são escoltadas por jipes militares até zonas fechadas. Mais tarde, iniciam a viagem para o Norte de Moçambique - província do Niassa - onde seriam reeducadas. Lá existiam os campos de reeducação mais conhecidos, mas não eram os únicos. Está documentado que em Inhassume, província de Inhambane, também houve um campo de reeducação.

Os marginais existentes nas cidades moçambicanas têm merecido da parte do Governo de Transição uma atenção muito especial. No Inhassume, por exemplo, existe um campo de reeducação. O referido campo funciona desde Dezembro do ano passado. (...) 160 marginais (...) No Inhassume já não existem marginais, existem Camaradas. (Machel, 1975, p. 47)

Da pesquisa oral feita, regista-se a canção de Sulemane Mohamed (Simeão Mazuze) intitulada "Bilibiza". Este lugar mencionado pelo músico seria um campo de reeducação que ele convida a visitar: "a hiyene hi ya vona: [Vamos ver, vamos visitar (um sítio terrível!), vamos ver!].

No filme Virgem Margarida, ao longo da viagem vão encontrando mulheres de outras cidades, que engrossam o grupo e são, também, levadas para o Norte do País, para espaços destinado à sua reeducação. É neste campo onde os eventos se multiplicam. O filme termina com uma revolução, melhor, uma sublevação negociada entre as comandantes e as reeducandas, depois de terem ganho consciência de que todas elas comandantes e reeducandas - eram vítimas de um sistema e da corrupção, neste caso masculina, representada por um comandante que compra favores sexuais em troca de alguns bens básicos como sabão e finalmente estupra Margarida para ter a certeza de que ela era virgem.

Entre memórias silenciadas (2013), uma espécie de reescrita da obra No reino dos abutres (2002), ambas de Ungulani, está dividida em actos da orquestra de marimba e centra-se em focos espaciais (lugares geográficos) representativos e significativos: (i) o campo (meio rural), num dos capítulos inaugurais "Mutsitso - 3 a 'Introdução Orquestral'", onde começa a história. "Um pouco impaciente, a velha ia acompanhando o vento na sua deambulação pelos nostálgicos tempos da juventude" (ba ka Khosa, 2013, p. 17). É o lugar de onde Lotasse, da linhagem dos Chibindzi, parte para a cidade, fugido, depois de os pais terem sacrificado Mpepo, o seu boi preferido, para um ritual familiar. É também, no "Mutsitso - Final Orquestral", o lugar onde acaba a história, com a chegada de Pedro, filho de Lotasse à aldeia natal do seu pai, onde a Grande Mãe, Jonasse e Feniasse o aguardavam; (ii) a cidade que é apresentada com a complexidade que lhe é característica em Moçambique, com bairros centrais, de cimento, e bairros periféricos, de caniço e zinco, cada um dos espaços com a sua dinâmica, espelhando a estrutura

\footnotetext{
' Na revista Tempo, $n^{\circ} 216$, de 17 de Novembro de 1974, Calane da Silva assina um artigo intitulado "Prostituição: primeiros e decisivos golpes". Na revista Tempo, n²38, de 20 de Abril de 1975, p. 36, começam a surgir notícias de sinais de rusgas nas cidades.
} 
social da então Lourenço Marques e que ainda se reflecte no Maputo de hoje; (iii) o campo de reeducação que se afigura um espaço aberto e simultaneamente fechado, como mais adiante discutiremos, é onde se destacam vozes e visões em conflito e que estabelecem elos espaciais e temporais, inscrevendo a dinâmica da história ou História e de memórias individuais e colectivas. No texto, percebemos uma dinâmica no enredo em que os espaços se definem de acordo com as condições sociais e com a cor da pele. De outras fontes, percebemos essa mesma realidade. Por exemplo, através de um discurso de Samora Machel, primeiro Presidente de Moçambique, que afirma "à medida que caminhamos do Ocidente para o Oriente, em Lourenço Marques, a cor da pele vai branqueando" (Machel, 1976). Esta afirmação de Samora Machel espelha uma realidade que consistia na configuração da cidade de acordo com a estrutura socioeconómica da cidade: a parte do cimento para os mais ricos, maioritariamente brancos, e a do caniço para os mais pobres, maioritariamente negros. Segundo Manuel Araújo (1999, p. 1177),

na linguagem popular, e segundo a formulação que se foi enraizando até se tornar em uso comum nos mais variados textos, a cidade de Maputo, como sucede com todas as urbes moçambicanas, é formada pela "cidade de cimento" e pela "cidade de caniço". (...) A "cidade de cimento" corresponde ao espaço da área urbana, enquanto o "caniço" constitui aquilo que são considerados os bairros suburbanos e, mais recentemente, os periurbanos.

As obras em estudo têm em comum aspectos que consideramos importantes. O primeiro é que exploram o universo e a dinâmica dos campos de reeducação ${ }^{2}$ numa perspectiva não só espacial, mas numa dimensão complexa entre o social, o psicológico e ideológico, projectando linhas de leitura que convocam, entre outras, as dimensões da memória e de um diálogo possível entre a literatura e o cinema e entre ambas e a História. Um segundo aspecto é a época, período histórico que se representa. Ambas centram o foco no período entre 1974 e 1988, referentes ao período do Governo de Transição3 aos primeiros anos da independência do país (1975-1988). Em jeito de "complementaridade" Virgem Margarida explora o mundo essencialmente feminino, enquanto que em Entre memórias silenciadas se explora numa proporção maior o mundo masculino. Esta aproximação sugere esta ligação que sai enriquecida em virtude de se tratar de narrativas que se sustentam em sistemas semióticos diferentes, uma vez que cada veículo comunicador - um romance e uma narrativa cinematográfica - trabalha com signos diferentes.

Há ainda outros aspectos que poderiam ser convocados para esta reflexão de forma mais profunda: a possibilidade de serem adjectivados como históricos, tendo em conta que, segundo Weinhardt (1995, p. 51),

\footnotetext{
${ }^{2}$ Historicamente, há pouca informação sobre o assunto. Não tendo encontrado uma definição académica, definiria campo de reeducação o espaço para onde os "marginais" eram para se corrigirem através do trabalho manual [esta definição resulta de pesquisas feitas no terreno]; Importa dizer que estes campos levantaram muitas questões relativas à legalidade e legitimidade e até propriedade (condições logísticas, higiénicas físicas e mentais) informação da autora.'

3 O Governo de Transição, liderado por Joaquim Chissano, como Primeiro Ministro, tomou posse em 20 de Setembro de 1974 e cessou a 25 de Junho de 1975, depois da proclamação da independência nacional.
} 
ao romance histórico não interessa repetir o relato dos grandes acontecimentos, mas ressuscitar poeticamente os seres humanos que viveram essa experiência. Ele deve fazer com que o leitor apreenda as razões sociais e humanas que fizeram com que os homens daquele tempo e daquele espaço pensassem, sentissem e agissem da forma como o fizeram. Trata-se de uma norma da figuração literária, aparentemente paradoxal, em que se alcança esta apreensão focalizando os detalhes do quotidiano que parecem insignificantes. (...) tensionada pela revolução, pode revelar forças, surgindo naturalmente os heróis que para a história são incógnitos.

Licinio de Azevedo inscreve, aliás, como nota na apresentação do filme que se inspirou em factos e personagens reais.

\section{DA RETÓRICA FUNDACIONAL, O PANO DE FUNDO: PERSPETIVAS}

A compreensão do contexto sociopolítico de Moçambique, representado nas obras, passa por uma reflexão em torno dos ideais de nação difundidos de modo envolvente, em comícios, nas escolas, em hinos revolucionários, através da rádio e outros meios de comunicação, incluindo o cinema (Manjate, 2017). A euforia da vitória contra o colonialismo português, a exaltação do triunfo da Luta de Libertação Nacional, a independência, a menção dos heróis e os anti-heróis como suporte material e ideológico fazem parte da retórica explícita e implícita muito presente nas obras em estudo. Ainda para ilustrar esta dinâmica, é de recordar a figura do "Xiconhoca, inimigo do povo" muito presente nos órgãos de comunicação social, nas escolas, nas reuniões de bairro, reflexo de um trabalho ideológico que pretendia transformar a sociedade através de uma linguagem simples e de modelos comportamentais não aceitáveis. O Xiconhoca simbolizava o "homem velho", a ser disciplinado, transformado ou mesmo combatido. Este conceito aliou-se às políticas de erradicação das figuras sociais que o governo definia como remanescentes do colonialismo e do capitalismo. Referia-se a prostitutas, consumidores de drogas, desempregados, entre outros, considerados improdutivos e nocivos para a nova nação independente.

Estas imagens têm como pano de fundo este universo triunfalista e reordenador, transformador, tendo como filosofia de base: a formação do "Homem Novo". Segundo Basílio (2011)

o "Homem Novo", figura política e ideológica imaginária, representou o princípio de uma nova identidade nacional, de um novo poder político e de novo Estado. Esta categoria orientou a formação de um Estado unitário, centralizado e provedor de direitos universais dos cidadãos. Os Estados de orientação socialista conservaram uma tradição revolucionária que foi caracterizando as atitudes de uma nova forma de conceber o mundo designada por "Homem Novo". (...) Na política moçambicana defendida por Samora Machel, a categoria do "Homem Novo", significava uma nova 
identidade, uma moçambicanidade fruto da luta pelo reconhecimento, uma moçambicanidade que nascia a partir da união de grupos diferenciados objectivando a formação de um só povo, uma só nação e um só Estado. O "Homem Novo" referia-se a um novo Estado independente e soberano formado por cidadãos: camponeses, operários, intelectuais e políticos; cidadãos honestos, trabalhadores e revolucionários que vivem e constroem relações harmoniosas.

Segundo Cabaço (2007, p. 412), foi nos primórdios da Luta Armada de Libertação Nacional, quando a preparação militar era complementada por um trabalho ideológico que se veiculavam novos valores para a construção de uma sociedade "justa, solidária, coesa, socialmente disciplinada, com uma visão económica fundada no princípio da auto-suficiência e dependente essencialmente das "próprias forças" e da "imaginação criativa do homem".

Esta visão, amplamente difundida, fazia parte da retórica mobilizadora e envolvente, e está representada em A última prostituta através do discurso inicial de um grupo em torno de fotografias apresentadas por R. Rangel. "Quando os soldados entraram em Maputo, todos nós os aclamámos (...) também as prostitutas. Esta fotografia foi tirada semana(s) antes de o governo decretar o fim da prostituição, isto é, proibir a prostituição" (um dos pronunciamentos de Rangel em $A$ última prostituta).

O momento captado sugere uma fissura ou mesmo ruptura entre dois universos representados nas imagens: o antes e o depois do fim da era colonial.

Em Virgem Margarida, esta retórica está imanente nos panfletos, nas canções revolucionárias, nos discursos oficiais das comandantes, na preocupação pela formação político-ideológica e mais tarde, no texto das reeducandas por elas escrito e lido na recepção do comandante Felisberto, como demonstração do efeito ou reflexo de transformação operada a nível das mentalidades e, consequentemente dos comportamentos.

Entre "Vivas" e "Abaixos"4, e em comparação insistente com o período da Luta Armada de Libertação Nacional e com as zonas libertadas ${ }^{5}$ espaço-modelo, a retórica da regeneração, da edificação de um mundo novo se reiterava.

Há que distinguir dois momentos fundamentais: o processo de perseguição às prostitutas e a "Operação Produção", iniciada em 1983 e terminada em 1988. O combate à prostituição iniciou-se ainda no Governo de Transição, em 1974, como testemunha o artigo de Calane da Silva com o título "Prostituição: os primeiros e decisivos golpes" (Calane da Silva, 1974). A Operação Produção visou idealmente também pessoas com outros perfis.

\footnotetext{
${ }^{4}$ Os discursos políticos normalmente iniciavam com expressões que exigiam a resposta do público presente: "Viva XXXX" resposta "VIVA!"; "Abaixo os XXX". Resposta: ABAIXO!

5 "À medida que a luta de libertação nacional avançava, o regime colonial abandonava as regiões, concentrando a sua administração nas zonas urbanas. As zonas abandonadas e tomadas pelos guerrilheiros passaram a designar-se por zonas libertadas. As primeiras Zonas Libertadas surgiram em Cabo Delgado e Niassa e, mais tarde nas províncias de Manica e Sofala". Retirado de http://4Oanos-dev.portaldogoverno.gov.mz/por/Luta-de-Libertacao/Zonas-Libertadas
} 
A Operação Produção (OP) foi um programa iniciado pelo Governo moçambicano nos meados de 1983, logo após ao IV Congresso do partido FRELIMO, para expulsar (palavra certa) coercivamente os desempregados das grandes cidades, e enviá-los para remotas zonas rurais, onde, pelo menos, teoricamente iriam cultivar. (Darch, 2017, p. 9)

Em Entre memórias silenciadas (2013) esta retórica é apresentada a partir de imagens-símbolo, evidenciadas pelo narrador em actos e visões da Mamã Grande, como lhe chama Pedro, filho de Lotasse.

E com a leveza dos espíritos nunca vistos passou o corpo pelo tampo da mesa, estendeu a mão pelas cadeiras sem pés e braços, atirou os olhos sem as íris aos velhos trastes em agonia, roçou com a língua a esteira esburacada, desarrumou os copos e os pratos partidos em tempos de fartura, deslocou das paredes de adobe fotografias dos calendários de anos comuns e bissextos, espantou as baratas excitadas, expulsou o ar amordaçado na sala desde os tempos de vozes ciciadas pelo medo da autocrítica - reprimenda que consistia na confissão pública, entre outros males, das modalidades extraconjugais ante o riso e a avidez dos chefes fardados com a balalaica única do partido único. (ba ka Khosa, 2013, p. 17)

Para trás ficaram as colunas de carros guiados por militares fardados e desfardados, sustentando uma guerra desgastante e ideológica e cultural (...) para trás ficara, as vozes e os discursos sussurrados dos amigos desnorteados com o tempo presente, em bares e cafés e ruas e becos, sempre com olhar inquieto, perscrutando delatores invisíveis; para trás ficaram as casas nacionalizadas mudando a geografia das classes e camadas (...); para trás ficaram as cancelas sem fim dos guetos dos chefes do povo... (ba ka Khosa, 2013, p. 217)

Fica patente que, entre a idealização e os discursos eufóricos e utópicos, inscrevem-se outras linhas de pensamento - de ver, pensar e sentir - dissonantes, disfóricas e distópicas. Como nos diz Darch (2017, p. 9),

a Operação Produção não foi de modo nenhum uma resposta inusitada pelo governo, enfrentando um problema de insuficiência desestabilizadora do "lumpemproletariado", ou seja, uma subclasse urbana fora das estruturas normais de controlo. Foi, sem dúvida, uma resposta extrema e que resultou em rupturas sociais em larga escala.

As duas narrativas desconstroem as visões idealizadas, idílicas mesmo, que os discursos oficiais apregoavam e instituíram. A partir das narrativas, inscrevem-se, deste modo, vozes e visões críticas às práticas do regime instalado. As duas narrativas podem ser assumidas como representação de um discurso não-oficial e sobretudo crítico do 
discurso largamente difundido pelas instâncias governativas. Revelando bolsas sociais diversas, acostam-se em visões múltiplas e cruzadas e inscrevem, cada uma a seu modo, a apelar para uma reflexão em torno de memórias aparentemente votadas ao silêncio.

\section{OS ESPAÇOS E AS MEMÓRIAS}

Segundo Aguiar e Silva (1988, p. 598), todo o texto narrativo, independentemente do(s) sistemas semiótico(s) que possibilitam a sua estruturação, especifica-se por nele existir uma instância enunciadora que relata os eventos reais ou fictícios que se sucedem no tempo - ao representar eventos, que constituem a passagem de um estado para outro estado; o texto narrativo representa também necessariamente estados, originados ou sofridos por agentes antropomórficos ou não, individuais ou colectivos, e situados no espaço do mundo empírico ou de um mundo possível.

Do conjunto das categorias apresentadas, o espaço é uma das categorias mais importantes não só pelas articulações funcionais que estabelece com as restantes categorias - tempo, agente, acção - como também pelas incidências semânticas que o caracterizam (Reis \& Lopes, 2002, p. 129).

Como categoria narrativa, o espaço é detentor de inegáveis potencialidades de representação semântica; pode ser entendido como um signo ideológico ao inscrever a presença explícita ou implícita de atributos de natureza social, económica e histórica, articulando com outros sinais de acordo com o sistema ideológico que a narrativa apresenta de forma predominante.

Como categoria, o espaço pode actuar como referência para análise destas obras ficcionais, no sentido em que dela derivam segmentos que podem reunir múltiplas perspectivas ou dimensões: espaço rural e da ancestralidade, urbano com os seus contrastes, espaço da memória e da intersubjectivação, e o da imanência de desterritorialização. Estes recortes não esgotam as dimensões que os textos oferecem. Deles decorrem reflexões sobre o espaço literário, o espaço ocupado por narradores a quem se podem aferir posicionamentos éticos e estéticos em relação à matéria narrada e às vozes narrativas que privilegiam.

Os espaços das narrativas, elementos aparentemente autónomos, rural e urbano, susceptíveis de descrições variavelmente pormenorizadas, ganham contornos sociais, económicos, psicológicos, até politico-ideológicos, sem, contudo, deixarem de ser contextos de enquadramento para eventos e comportamentos.

Nos textos em análise, o espaço impõe-se como um intenso foco de irradiação semântica, confere valores e molda os sujeitos e os tempos. O vínculo espacial, neste caso coincidente, chama a atenção para esta categoria narrativa e para a complexidade e para a carga simbólica que cada um projecta e inscreve.

A noção de espaço, associada à de tempo faz prevalecer o sentido em que memórias anteriores fornecem fortes valores relacionados a espaços. Através das narrativas, vive-se um presente e simultaneamente um passado, pelos resquícios memoriais e pelas representações baseadas, em parte, no repetir de experiências de acções passadas. 
Em Entre memórias silenciadas, o primeiro espaço, a aldeia, ao mesmo tempo que é de protecção é também de evasão, isto é, de fuga e de reencontro, onde as tradições estão vivas. É representado pela figura da mulher centenária, pelo gado bovino e pelo canhoeiro, árvore sagrada, marcos da religiosidade Bantu. É de onde Lotasse foge e é também o espaço para onde Pedro, descendente daquele, vai depois de pesadelos insistentes, a conselho de um curandeiro, em estreita ligação com sinais premonitórios presentes no início e no final do texto, em prolepse. "A guerra, a devastação, estava para os outros. Para a velha, o Jonasse, a Feniasse, o gado e os cães, a guerra era outra: o cio (ba ka Khosa, 2013, p. 20).

Pedro avistou uma vila familiar que se quis inteira e feliz. À medida que em passos de inquietação, se aproximava, um estranho vento açoitava-lhe o corpo, como que a acordá-lo para uma realidade desconhecida. Ao centro, erguendo-se sobre as demais árvores, estava o grande canhoeiro dos antepassados, a árvore sagrada, ponto central das tradicionais cerimónias de evocação dos espíritos de toda a linhagem... (ba ka Khosa, 2013, p. 220)

Gaston Bachelard em A poética do espaço toma a casa como concha refúgio essencial, abrigo primeiro, o ventre, onde "o ser reina numa espécie de paraíso terrestre da matéria, fundido na doçura de uma matéria adequada" (1978, p. 201). É o espaço de acolhimento e recolhimento. A casa simboliza o espaço de eleição, onde se materializa a protecção, o reencontro com as raízes, onde se revisitam os laços familiares, neste caso, do passado.

A aldeia, casa de Lotasse é ponto de partida, no entanto, nunca esquecido. É também ponto de chegada de Pedro, filho daquele. É o símbolo do ventre materno, de onde se nasce, onde se tem proteção. É um espaço sagrado. É um lugar de memórias e de reencontro com um passado distante e desconhecido para Pedro, filho de Lotasse. Aqui o tempo interfere com a noção de espaço no sentido em que memórias anteriores fornecem fortes valores e sentimentos aos espaços. Neste processo, e retroativamente, espaço, lugares e paisagem têm um papel crucial no moldar da memória individual e, desta forma, também na memória colectiva (Martins, 2015).

O campo distante, o gado em combates de apostas adolescentes, as histórias da mãe em redor de míticas fogueiras, as insuspeitas interjeições, as onomatopeias de ocasião, eram memórias em desgrudamento crescente na mente em delírio com fitas de magia que fazia rolar horas de sonho na expectante plateia de brancos. (...) Lotasse vivia os seus anos de áurea imaginativa, se paraíso edificado à base de imagens que passavam na tela. Sonhava. (ba ka Khosa, 2013, p. 27)

Rahinovich, num artigo intitulado "A casa como símbolo: a relação mãe-criança" (1997), toma a casa como um símbolo, em primeiro lugar, porque ela substitui o útero, nas suas funções de protecção, sendo uma extensão e um reflexo da maternidade. $A$ aldeia, na obra Entre memórias silenciadas é "o lar dos Chibindzi", permanece como uma 
espécie de símbolo original: pois denota a origem-útero-terra, e conota a vida relacional. Ela manteve-se incólume aos contactos com as novas realidades que "enfermavam" as cidades.

Em referência à cosmologia operante nos indivíduos, Pedro deixa os fantasmas da cidade após pesadelos reiterados com baratas fazendo sexo e mutilando-se. O sonho seria um sinal interpretado por um curandeiro como chamamento para as origens, e que se "limitou a indicar o caminho da ancestralidade desconhecida, aos avós de que não tinha memória, à mátria terra de campas estranhas e obliteradas pela revolução" (ba ka Khosa, 2013, p. 218). Aqui, entram em sintonia muitos elementos simbólicos que configuram aquele lar: as árvores sagradas, as "campas estranhas e obliteradas pela revolução" (ba ka Khosa, 2013, p. 219). Todo um conjunto de elementos que reconstroem um imaginário que urge reedificar.

Deixando para trás "o cimento, fardas, discursos, cafés, casas nacionalizadas, grupos dinamizadores, comprometidos", Pedro "volta" à aldeia, sem nunca ter saído. A aldeia é a terra da família Chibindzi, lugar sagrado que há muito o aguardava. Sob orientação de Jonasse, escolhe um boi, a quem dá o seu próprio nome e, assim, inscreve a linha de continuidade interrompida pelo pai, Lotasse.

A aldeia natal é o lugar para onde Margarida, personagem principal de Virgem Margarida, não quer voltar por se sentir impura e imprópria para o habitar. A casa de onde partira, o seu universo rural não acolhe o profano ou o profanado. Em algumas sociedades, a virgindade simboliza pureza. Depois de desvirginada, vítima de agressão sexual, do comandante Felisberto, Margarida sente que não pode voltar à aldeia, à casa, espaço sagrado, de onde saíra imaculada, por se considerar impura, dessacralizada por um homem da nova ordem. A casa, neste caso, é um santuário que, no seu entender, não merecia receber um membro tocado e marcado por eventos degradantes. Metonimicamente, o acto, ainda que involuntário, macula o sujeito também. Segundo Mondlane e Clerck, em Chitlango, filho de chefe (1990), na cultura Bantu, o desvio ou acto insano de um membro pode afectar de forma negativa toda a comunidade.

$O$ fruto venenoso que Margarida colhe no final representa a possibilidade de uma evasão através da morte, uma fuga para lugar nenhum: não fica no campo de reeducação porque foi desmantelado e não volta para a aldeia, o universo uterino. É um estado de ruptura total que elimina qualquer espaço, como afronta e incriminação ou mesmo diabolização de um sistema que roubara a pureza e os sonhos de uma mocidade interrompida.

A morte aqui afigura-se como uma evasão, uma fuga para um não-espaço, lugar-nenhum, em oposição aos espaços físicos que Margarida rejeita. Neste caso, subentende-se como a recusa ou impossibilidade de a personagem se integrar num espaço específico - campo de reeducação, campo (aldeia de origem) ou cidade (espaço de passagem). Os espaços anteriores - a cidade, não a acolheu e o campo de reeducação a profanou. Na cidade, foi coercivamente recolhida por não ter documentos e no campo de reeducação, ao mesmo tempo que contribuiu uma socialização e uma solidariedade imprevisíveis não se elegeu como espaço de realização efectiva e afectiva. No início, 
Margarida foi questionada e julgada pelas co-reeducandas e pelas comandantes, mas no final Margarida conseguira despertar um sentido de forte solidariedade que culminou com a sublevação. Os dois espaços, a cidade e o campo de reeducação, inscrevem-se aqui como espaços de negação, inférteis em termos de edificação da personagem, como símbolo.

Em entrevista com Marta Lança, publicada no jornal Público, Licinio de Azevedo afirma:

o verdadeiro grito revolucionário provém das militares quando dizem "filho da puta, passou para o lado do inimigo". [A comandante Maria João] revoltada, usa a linguagem das prostitutas, coloca-se contra os homens, pois o militar, afinal, é um símbolo masculino reacionário. Já elas dão continuidade à revolução, depois de perceberem que estão a ser julgadas, de maneira indecente, pelo lado machista da revolução. A militar torna-se a verdadeira juíza da revolução. (Lança, 2012, s.p.)

Em Entre memórias silenciadas, a morte, a morte como um não-espaço, também está muito presente.

O velho Tomás está a meu lado. É o meu companheiro de destino. O cabelo e a barba tornaram-se tão brancos que todos o reconhecem à distância. É o homem mais antigo do campo. O comandante há muito que o reformara das actividades do campo. E para ocupar o seu tempo, vai pintando, nas palhotas dos mortos, cruzes de tamanhos e cores diferentes. A quantidade de mortos é tão elevada que as cruzes se sobrepõem em configurações geométricas tão ou mais abstractas que as telas da nossa pintora Bertina Lopes. (ba ka Khosa, 2013, p. 50)

Tornou-se fundamental, pela mão de Tomás, ao desenhar cruzes e das sementeiras das maçarocas no lugar dos sepulcros "eternizar" um espaço perdido de forma definitiva pelos mortos e. manter, de forma simbólica a continuidade ou a territorialização, isto é, manter um espaço, através da memória.

Em Virgem Margarida, a cidade é vista muito rapidamente, registando, no entanto, uma dinâmica intensa e diversa. No cimento o labor e a vida nocturna intensa: prostitutas, artistas, boémios, uma cidade frenética. O subúrbio é a fonte de onde saem as prostitutas, as artistas e para onde voltam no final de cada noite. No subúrbio está a vida familiar, onde ficam as mães e os filhos à espera. É onde a pobreza e os problemas do dia-a-dia de vivem. A cidade de cimento constitui a expectativa do dinheiro, a promessa da resolução dos problemas.

Em Entre memórias silenciadas, a cidade envolve muitos universos, estruturas sociais bem definidas, moldando a vida dos sujeitos. Entre o quintal, onde Lotasse primeiro trabalhou, como empregado doméstico, e depois a urbe, como ajudante de projectista no cinema Gil Vicente, estes espaços determinam categorias sociais. A cidade de cimento e o caniço, os subúrbios. "Lourenço Marques crescia a olhos vistos" (ba ka 
Khosa, 2013, p. 27). "Lotasse, agora, na casa dos trinta, dava-se conta que vivia na outra margem, na zona do Alto Maé, local não contabilizado nas matemáticas do crescimento económico porque desprovido de infra-estruturas básicas nas contas das despesas públicas (ba ka Khosa, 2013, p. 33).

É nos campos de reeducação representados nas obras que se regista a grande parte dos eventos. É o lugar onde se revelam os conflitos entre uma ordem e um caos e a tentativa de uma reordenação e de transformação. É um espaço aberto - não havia muros nem vedações, mas é simultaneamente fechado: as pessoas não se podem mover livremente, não podem abandoná-lo. É uma prisão. "Todos sabiam, por experiência contada, de que pouco servia fugir do campo, porque seríamos presas fáceis de leões e leopardos, para não falar de crocodilos com as mandibulas insatisfeitas, infestando o leito dos rios" (ba ka Khosa, 2013, p. 56).

Em Virgem Margarida, as mulheres, todas elas - as reeducandas e as reeducadoras - são prisioneiras. No dizer de Rosa, personagem rebelde, são todas prisioneiras e são, sobretudo, escravas: "somos escravas sem dono. Mais, vocês (as comandantes) também o são".

As mulheres não podem dizer o que pensam. Quando o fazem, são castigadas. Mas as comandantes também não têm escolha: elas também não querem estar naquele lugar. Também têm os seus sonhos que são marginalizados e adiados. No fundo assiste-se, igualmente, a factores de manutenção de certos valores ligados à tradição, fazendo uso dos recursos acumulados no passado. Na verdade, perante um movimento amplo que pretendia incutir transformações profundas nas relações sociais, as práticas tradicionais não parecem ter sofrido mutações de fundo nem se dissiparam, passaram simplesmente para a clandestinidade para contornarem o desencorajamento contido no discurso político (Andrade, Osório \& Trindade, 2000).

O reavivar das expressões culturais num contexto em que a tradição se havia ajustado a novas realidades resulta num processo de agravamento da posição subalterna da mulher, pois certos aspectos desta são sujeitos a uma filtragem e decorrem das habilidades e capacidades de manipulação dos que a transmitem (Loforte, 2003).

O medo e a proximidade da morte, os castigos, a presença próxima de animais ferozes, a fome e a sede, sempre presentes mantinham as reeducandas e as reeducadoras num ambiente entre a hostilidade e a solidariedade.

Expressões como "disciplina", "indisciplina", "punição" fazem parte do campo de reeducação, um espaço de coerção e protecção. A comandante Maria João, bastião da ordem e do poder, pune, na intenção de reabilitar aquelas mulheres. O convívio, a partiIha de sentimentos e experiências, algumas traumáticas, faz com que se operem transformações tão profundas que fazem com que no final se reconheçam e se partilhem sentimentos. Elas, unidas e incrédulas, banem a bandeira que as conduziu para aquele espaço. Todas elas clamam por uma libertação.

O filme é sobre os antagonismos da sua libertação. Remete para a emancipação das mulheres africanas em situações distintas: alfabetizadas ou não, a mulher colonizada e a mulher revolucionária, que percebe a disciplina 
imposta pelo homem. A reeducação funciona em vários sentidos, todas se "purificam" num certo dualismo: as prostitutas purificam-se porque aprendem coisas como a importância da liberdade e do trabalho, as militares libertam-se das hierarquias superiores. A adolescente virgem torna-se uma espécie de santa: todas a querem proteger ou ser protegidas por ela, profunda conhecedora do mato, ao contrário das mulheres urbanas sem relação com o mundo rural. A reeducação de prostitutas, militares e camponesas foi afinal um processo de mútuo conhecimento, que as leva a unirem-se para se libertarem. (Virgem Margarida, 2012)

Em Entre memórias silenciadas o cenário não é diferente. As conversas são soturnas, entre as memórias e o futuro distante e incógnito. Depois do campo de reeducação a partida para Unango, cidade do futuro, e a evasão nos corpos femininos, a fuga do medo, das incertezas do desconhecido, as expectativas começam a ganhar forma. Os contornos de novos discursos e novos conceitos, catapultam a imaginação dos prisioneiros. As redefinições de existências com condicionalismos quer discursivos, quer estruturalmente mais práticos ditam novas conjunturas, apesar de ser em circuito fechado. Apesar de se ter fechado o campo de reeducação, os mulheres e homens aparentemente livres não podem voltar para casa. Têm de ficar para materializar um sonho de se fundar uma cidade nova, a cidade do futuro: Unango.

Nas duas obras, observa-se que o espaço é tratado não apenas como categoria identificável, mas como sistema interpretativo, modelo de leitura. Cada um dos espaços imprime uma dinâmica, visões, moldando personalidades e comportamentos dos agentes. Numa perspectiva mais profunda, cada um dos espaços é um lugar do ser existencial em desassossego ou em conflito.

Os campos de reeducação, por exemplo, de uma forma intensa, fazem convergir e convocam simultaneamente muitas linhas que vão desde as causas à filosofia do "Homem Novo" e o combate aos vícios das cidades como a prostituição, a boémia, a improdutividade, substantivos tão presentes na retórica oficial, nos anos após a independência. A complexidade do registo de eventos como pintar cruzes nas portas das palhotas dos mortos, um ritual do velho Tomás, convocam um exercício de memórias que se reinventam em momentos de incerteza e de desespero. As conversas que, afinal faziam a ponte entre um passado conhecido e o presente distante e incerto de cada um dos presentes, numa inscrição de lembranças que era necessário resgatar fazem constantemente um apelo à rememoração de eventos e realidades novas e antigas. Eram afinal uma forma de sobrevivência de criação de laços e de memórias.

A memória, a priori, parece ser um fenómeno individual, algo relativamente íntimo, próprio da pessoa, que se partilha ou não. Porém ela deve ser entendida também, ou sobretudo, como um fenómeno colectivo e social, ou seja, como um fenómeno construído colectivamente e submetido a possíveis flutuações, transformações e mudanças. Se os reeducandos, as reeducandas e os comandantes podiam ser entendidos como ilhas fechadas, no final podem ser entendidos como um bloco com características próprias, 
como um grupo incontornável. Inscreve-se aqui um conflito entre o discurso ou a História oficial e outras que urge resgatar para uma melhor composição do que se chama cultura moçambicana, de forma holística.

Pensar a memória não é, simplesmente, entrar no passado e encontrar eventos, factos, pessoas, lugares em que se tenha vivido em algum momento. É muito mais complexo. Na realidade, a memória aqui se refere à memória colectiva, isto é, à lembrança de um grupo que viveu e conserva, como património certos acontecimentos em comum, como, aliás, se entende o grupo que partilhou o destino nos campos de reeducação.

Pollak, em "Memória e identidade social" (1992, p.10), adianta três elementos que directa ou indirectamente constroem as memórias, tanto individuais como colectivas, nomeadamente, os acontecimentos, as personagens e os lugares. Aqui os espaços, matéria da topoanálise sugerida por G. Bachelard, através do fluxo sequencial ajudam na leitura que tem em conta as simultaneidades, os mapeamentos que possibilitam entrar na narrativa quase que em qualquer ponto, sem perder de vista o objetivo geral: criar modos mais criticamente reveladores de examinar a combinação entre espaço e tempo, história e geografia, período e região, sucessão e simultaneidade. Nas duas narrativas, num só tempo, a sociedade vive um presente mas também um passado, pelos resquícios memoriais de outrora e, em parte, na repetição de experiências de ações passadas. Segundo Martins (2015), relembrando eventos ocorridos num determinado espaço, a memória que prevalece, na maior parte dos casos, é regida pelo tempo mental, ao invés da percepção temporal cronológica. Assim, uma abordagem sobre a memória como um fenómeno complexo, é importante para se entender como as sociedades e comunidades alimentam e desenvolvem as suas percepções através do sentido dos espaços e lugares projectados e representados.

Para que as memórias sejam consistentes, não basta que se partilhem depoimentos, é necessário que ela não tenha cessado de concordar com as memórias do grupo e que haja bastantes pontos de contacto entre uma e outra, para que as lembranças visitadas possam ser reconstruídas sobre um fundamento comum. Refere-se à necessidade da harmonização entre diferentes membros do grupo para que a memória possa, assim, ser reconstruída.

Desta breve reflexão que cruza as temáticas da espacialidade e da memória, fica uma questão; a razão das duas obras terem surgido quase simultaneamente, com a inscrição clara em Virgem Margarida, que se inspira em acontecimentos e pessoas reais. Entre memórias silenciadas é um título, que de per se, através do adjectivo "silenciadas" convoca a uma reflexão: o silenciamento deverá ser entendido como marginalização ou apagamento?

\section{EM JEITO DE CONCLUSÃo}

Uma das emergências actuais inscreve uma estreita relação entre os estudos culturais e a literatura - motivo que transcende o interesse de contextualizar a literatura nas perspectivas históricas e culturais - surge não só pela inclusão crescente de textos 
ficcionais e literários nos estudos da cultura e pelo interesse nas formas representativas e as suas relações com a constituição de identidades culturais.

As obras em estudo Virgem Margarida de Licinio de Azevedo e Entre memórias silenciadas de Ungulani ba ka Khosa têm vários aspectos em comum. Para além de explorarem aspectos das filosofias de vida em Moçambique, desde as relações de género, as relações de poder e da disposição sociogeográfica, entre outras, exploram as experiências vividas em campos de reeducação na província do Niassa. Exploram também trajetórias campo-cidade, a vida urbana e suburbana de mulheres e homens que foram recolhidos das cidades e mandados para o Niassa, para campos de reeducação. Nas narrativas, o espaço transcende o meramente geográfico, configuram-se como conjunto de factores sociais, económicos e ideológicos que envolvem e transformam as personagens. São espaços de concentração dramática, ao mesmo tempo que são lugares de fuga, de memória, de realização e de irrealização. São lugares de encontros e desencontros, na medida em que exploram edificação de ideais e, ao mesmo tempo, o seu questionamento. São lugares de rupturas e de desconstrução, pois os leitores são convocados a reflectir sobre aspectos da vida nacional representada e que não são abordados nos manuais oficiais da História e da cultura. A partir das concepções e construções presentes nas obras, os espaços, particularmente os campos de reeducação convocam reflexões profundas que parecem estar condenadas ao esquecimento.

As relações espaciais constituem-se, pois, um meio fundamental para a percepção das dinâmicas representadas. A partir das concepções e construções presentes nas obras, os espaços convocam reflexões que parecem estar esquecidas na sociedade.

\section{REFERÊNCIAS}

Aguiar e Silva, V. M. (1988) Teoria da literatura. Coimbra: Almedina.

Andrade, X., Osório, C. \& Trindade, J. C. (2000). Quatro questões sobre os direitos humanos das mulheres. Revisão da literatura. Maputo: WLSA Moçambique.

Araújo, M. (1999). Cidade de Maputo. Espaços contrastantes: do urbano ao rural. Finisterra, 34(67/68), 175190. https://doi.org/10.18055/Finis1694

Azevedo, L. (Realizador). (1999). A última prostituta [Filme]. Moçambique: Ébano Multimédia.

Azevedo, L. (Realizador). (2012). Virgem Margarida [Filme]. Moçambique, Portugal e França: Ébano Multimédia, Ukbar Filmes e JBA Production.

Ba ka Khosa, U. (2002). No reino dos abutres. Maputo: Imprensa Universitária.

Ba ka Khosa, U. (2013). Ente memórias silenciadas. Maputo: Editora Alcance.

Bachelard, G. (1978). A poética do espaço. São Paulo: Martins Fontes.

Basílio, G. (2011). Samora Machel: o princípio do Homem Novo e seus significados. UDZIWI: Revista da Educação, 7. Retirado de https://www.revista.up.ac.mz/index.php/UDZIWI/article/view/173/178

Calane da Silva, R. (1974). Prostituição: primeiros e decisivos golpes. Tempo, 216, 36. 
Darch, C. (2017). Prefácio a Poder do Poder: operação produção e a invenção dos "improdutivos" urbanos no Moçambique social, 1983-1988. Maputo: Carlos Quembo.

Halbwachs, M. (2013). A memória coletiva. São Paulo: Centauro.

Lança, M. (2012, 10 de setembro). Reeducação de mulheres, entrevista a Licínio Azevedo sobre o filme "Virgem Margarida". Buala. Retirado de http://www.buala.org/pt/afroscreen/ reeducacao-de-mulheres-entrevista-a-licinio-azevedo-sobre-o-filme-virgem-margarida

LeGoff. J. (2003). História e memória. São Paulo: Einaudi.

Loforte, A. (2003). Mulher, poder e tradição em Moçambique. Maputo: Outras Vozes.

Machava, B. (2011). State Discourse on Internal Security and the Politics of Punishment in PostIndependence Mozambique (1975-1983). Journal of Southern African Studies, 37, 593-609. Retirado e https://tinyurl.com/y6lge8jl

Machel, S. (1974). A mensagem do Presidente. Tempo, 209, 11-15.

Machel, S. (1975, 20 de abril). Inhassume: criar o Homem Novo. Tempo, 238, p. 47.

Machel, S. (1976, 3 de fevereiro). Discurso do Presidente Samora Machel do dia dos heróis moçambicanos. Notícias [Maputo].

Magaia, A. (1974). Prostituição: tráfico de sexo mata fome. Tempo, 210, 21-23.

Manjate, T. (2017). Virgem Margarida e a Última prostituta: a morte das fronteiras entre documentário e a ficção? Revista Mulemba, 9(17), 112-121. Retirado de https://revistas.ufrj.br/index.php/mulemba/issue/ view/826

Martins, R. (2013). Narrativas de lugar e memória: a importância de crescer o espaço na identidade do sujeito. Geo-Working Papers, 23, 5-24. Retirado de http://www.lasics.uminho.pt/ojs/index.php/ geoworkingp/article/view/1850/1780

Mondlane, E. \& Clerck, A-D (1990). Chitlango, filho de chefe. Maputo: Cadernos tempo.

Nora, P. (1993). Entre memória e história. A problemática dos lugares. Projeto História, 10, 7-28. Retirado de https://revistas.pucsp.br/revph/article/view/12101

Pollak, M. (1989). Memória, esquecimento, silêncio. Revista Estudos Históricos, 2(3), 3-15. Retirado de http:// bibliotecadigital.fgv.br/ojs/index.php/reh/article/view/2278

Pollak, M. (1992). Memória e identidade social. Revista Estudos Históricos, 5(10), 200-215. Retirado de http:// bibliotecadigital.fgv.br/ojs/index.php/reh/article/view/1941

Quembo, C. (2017). Poder do poder: operação produção e a invenção dos "improdutivos" urbanos no Moçambique social, 1983-1988. Maputo: Alcance Editora.

Reis, C. \& Lopes, C. (2002). Dicionário de narratologia. Coimbra: Almedina.

República de Moçambique (s.d.). Memórias da luta de libertação nacional. Retirado de http://40anos-dev. portaldogoverno.gov.mz/por/Luta-de-Libertacao/Zonas-Libertadas

Weinhardt, M. (1995). Considerações sobre o romance histórico. Revista de Letras, 43, 49-59. Retirado de https://revistas.ufpr.br/letras/article/view/19095 


\section{NOTA BIOGRÁFICA}

Teresa Manjate é doutorada em Literatura Tradicional e Oral pela Universidade Nova de Lisboa. Atualmente é investigadora no Centro de Estudos Africanos, e docente na Faculdade de Letras e Ciências Sociais, na Universidade Eduardo Mondlane em Maputo. Lecionou na África University (Zimbabwe), na Universidade da Suazilândia e na Universidade Politécnica (Maputo). É membro do Instituto de Estudos de Literatura e Tradição (IELT) e da Associação Internacional de Paremiologia (AIP).

Email:manjatet@gmail.com; teresa_manjate@hotmail.com

Morada: Universidade Politécnica, 1011 Avenida Paulo Samuel Kankhomba, Maputo, Moçambique

* Submetido: 13-09-2018

* Aceite: 02-01-2019 